
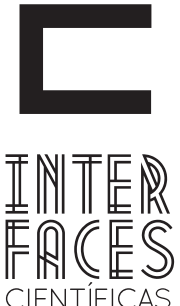

CIENTÍFICAS

HUMANASE SOCIAIS

\title{
GEOGRAFIA, TURISMO E EDUCAÇÃO AMBIENTAL NO MUNICÍPIO DE PIRAMBU-SE: UMA ESTRATÉGIA PARA A VALORIZAÇÃO DA CONSCIÊNCIA ECOLÓGICA
}

Mariana Barbosa Andrade ${ }^{1}$

Ivelise Fernanda Silva de Santana ${ }^{3}$
Cialy Rolemberg Andrade ${ }^{2}$

Lício Valério Lima Vieira ${ }^{4}$

\section{RESUMO}

A elaboração desse trabalho constitui em uma análise sobre o município de Pirambu e sua Geografia, ressaltando a educação ambiental na construção da conscientização ecológica como proteção e preservação do meio ambiente. Buscou, também, analisar o desenvolvimento sustentável como uma alternativa para promover o equilíbrio entre o homem e a natureza. Outro fator importante que será tratado é a educação ambiental reali- zado pelas escolas, tendo a geografia e as ciências humanas como parte integrante da vida social, pois servem como contribuição para a preservação do meio ambiente.

\section{PALAVRAS-CHAVE}

Educação Ambiental. Geografia. Conscientização. 


\section{ABSTRACT}

The preparation of this work constitutes an analysis of Pirambu municipality and its geography, emphasizing environmental education in ecological awareness for protection and preservation of the environment. Also, aims to analyze the sustainable development as an alternative to provide the balance between man and nature. Another important factor that will be addressed is theenvironmental education carried out byschools, with the geography and the humanities as an integral part of social life, because they serve as a contribution to the preservation of the environment.

\section{KEYWORDS}

Environmental Education. Geography. Awareness.

\section{RESUMEM}

La elaboración de este trabajo constituye un análisis de la Municipalidad de Pirambu y su geografía, haciendo hincapié en la educación ambiental en la construcción de conciencia ecológica como protección y preservación del medio ambiente. Se buscó también, analizar el desarrollo sostenible como una alternativa para promover el equilibrio entre el hombre y la naturaleza. Otro factor importante que se tratará es la educación ambiental sostenida por las escuelas y la geografía y las Humanidades como parte integral de la vida social, serviría como una contribución a la preservación del medio ambiente.

\section{PALABRAS CLAVE}

Educación ambiental. Geografía. Conciencia.

\section{INTRODUÇÃO}

O turismo é uma atividade que tem mostrado grande crescimento nas ultimas décadas no Brasil, despertando interesse como alternativa econômica para as regiões onde estão concentradas áreas naturais, valorizadas pelo rico patrimônio histórico-cultural.

Apesar das suas potencialidades, a atividade turística não tem vindo acompanhada de um planejamento adequado, não tem proporcionado um diálogo com a participação local, nem tampouco o entrosamento entre vários segmentos envolvidos. Esse fato acabou criando inúmeros conflitos e entraves a um modelo de desenvolvimento. Dessa forma, à medida que a nova década se aproxima um dos maiores desafios da humanidade é o de manter uma relação harmônica entre o homem e o meio natural.

Diante desse contexto, a alfabetização ecológica desponta como estratégia de sobrevivência da huma- nidade, sendo esta capaz de compreender os princípios básicos da ecologia e viver de acordo com eles.

Partindo desse pressuposto, pretendeu-se investigar o seguinte problema de pesquisa: a geografia, o turismo e a educação ambiental contribuem para a valorização da conscientização ecológica no município de Pirambu?

0 trabalho teve como objetivo geral a análise das relações entre geografia, turismo e educação ambiental no município de Pirambu e como objetivo específicos a caracterização das paisagens geográficas do município de Pirambu; o levantamento dos elementos do turismo e do meio ambiente de Pirambu; o levantamento de programas e ações educacionais para a preservação do meio ambiente; a verificação das estratégias metodológicas utilizadas pelos professores de 
geografia e seus reflexos na valorização ambiental e conscientização ecológica; a verificação das relações entre a educação ambiental e o despertar da conscientização ecológica e preservação do meio ambiente do município de Pirambu; caracterização da relação entre turismo e o desenvolvimento econômico e a preservação do meio ambiente no município de Pirambu.

Para o desenvolvimento da pesquisa, adotou-se metodologia baseada no aprimoramento das ideias, a partir da pesquisa exploratória e descritiva, cuja finalidade é a descrição das características da população por meio da coleta de dados. Os instrumentos de coleta de dados são os meios utilizados para operacionalizar a pesquisa. Assim, nesta foram utilizados questionários, contendo perguntas abertas e fechadas. A população desta pesquisa é composta pelas pessoas que residem no município de Pirambu, que possui cerca de 7000 habitantes. Para que sejam feitas análises e posteriormente conclusões, foi necessário que os dados coletados nessa pesquisa sejam tratados, por isso utilizaram-se gráficos indicando o tempo de residência dos moradores da região; as condições de trabalho; a situação da comunidade; a contribuição do turista para a economia do município de Pirambu; a importância do turismo para a região; contato entre turismo e moradores; a melhora entre turismo e comunidade.

Seguem, portanto, os elementos teóricos que embasam o estudo, as análises dos resultados e levantamento de campo, seguidos pela conclusão do estudo.

\section{GEOGRAFIA, TURISMO E EDUCAÇÃO AMBIENTAL: RELAÇ̃̃ES E SIMBIOSES}

Podem-se estabelecer diversas relações entre Geografia, Turismo e Educação Ambiental, mas será útil nessa reflexão analisar o papel da Geografia na transformação da natureza e da cultura na construção das paisagens e espaços.

Faz-se necessário ainda compreender a ação do turismo sobre o meio ambiente e entender a ligação que há entre os ambientes naturais valorizados pelo turismo no espaço geográfico.

Vale ressaltar que o "equilíbrio entre a natureza e o turismo, em que a primeira constitui a matéria-prima para o segundo, necessita ser regulado e disciplinado" (CORIOLANO, 1996, p. 100). Com isso, somente existirá um equilíbrio entre a natureza e o turismo quando houver um relacionamento harmonioso entre esses dois.

Por turismo, pode-se entender, como uma prática social, que envolve o deslocamento de pessoas pelo território e que possui as paisagens geográficas como objeto de consumo. Em outra definição, é fortemente determinado pela cultura com atrativos, paisagens e lugares turísticos. Dessa forma Fourastié (apud, RUSCHMANN, 2001, p. 13), esclarece que:

\begin{abstract}
A palavra "turismo" surgiu no século XIX, porem a atividade estende suas raízes pela história. Certas formas de turismos existem desde as mais antigas civilizações, mas foi a partir do século XX, e mais precisamente após a Segunda Guerra Mundial. Que ele evoluiu, como conseqüência dos aspectos relacionados à produtividade empresarial, ao poder de compra das pessoas e ao bem estar resultantes da restauração da paz no mundo.
\end{abstract}

Pode-se entender que o turismo age como subproduto da cultura. Pois, o turismo visto como objeto de estudo manifesta-se sob tendência ainda não explorada pela cultura humana. Se por um lado, contribui para a preservação e valorização da cultura e do meio ambiente, por outro, acarreta na capacidade de 
degradar e transformar o espaço geográfico. É nesse contexto que Coriolano (1996, p. 94) destaca que:

Os seres humanos são partes integrantes da natureza e, portanto são capazes de criá-la. 0 homem apenas utiliza-se da natureza para transformá-la, com o intuito de modificar e produzir uma outra natureza, chamada de natureza socializada. É assim que ele produz o espaço turístico.

A palavra turismo surgiu no século XIX, porém considera-se a atividade existente desde as mais antigas civilizações. Do ponto de vista da geografia, é possível relacionar o turismo com conceitos veiculados as saber geográfico (como natureza, paisagem, lugar e território). 0 turismo movimenta cada vez mais um numero maior de pessoas e de capital, representando assim importante fonte de renda e empregos.

O turismo é hoje a terceira maior fonte de renda do mundo. Portanto sua prática deve ser monitorada de modo que não se torne em mais uma ameaça ao meio ambiente, ainda que, seja difícil a sua identificação como tal devido ao seu caráter social voltado ao lazer (MIDAGLIA, 1999, p. 27).

Dessa forma, Ruschmann (2001, p. 167) destaca que:

Quanto ao crescimento do turismo internacional nos paises em desenvolvimento, a OMT prevê um crescimento favorável, motivada principalmete pelo interesse de produtos turísticos novos ou renovados, tais como o turismo rural, o turismo de aventuras, o ecológico e o turismo de brando (sanfler tourismus). Esse tipo de turismo leva a um contato mais estreito com o meio natural e humano e hábitos e costumes dos povos das localidades visitadas.

Segundo Martins (1996), o turismo pode ser entendido como uma experiência geográfica na qual a paisagem se constitui num elemento essencial. Rubio (ano) conceitua o espaço turístico como assento da oferta turística, um espaço concreto e objetivo, tendo seu valor recreativo variando em função de certas circunstâncias, entre elas o atrativo paisagístico. Para Almeida (1999, p. 184),
A ideologia básica do turismo se justifica na necessidade da busca de novos ambiente para a reposição da energia física e mental. Ora, para tal propósito a natureza, em especial as unidades naturais específicas do litoral, tornou-se o "recurso-turistico" mais explorado pelo capitalismo, a partir da segunda metade deste século. A natureza tornou-se mercadoria e é vendida como capaz de devolver ao homem a paz e a tranqüilidade roubadas no dia das cidades.

Atualmente o turismo é considerado como uma indústria que depende da apropriação e exploração da natureza e das sociedades locais, provocando muitas vezes uma degradação ambiental e sócio-cultural. Nesse sentido Carlos (1996, p. 26) destaca que:

A indústria do turismo transforma tudo o que toca em artificial, cria um mundo fictício e mistificado de lazer, ilusório, onde o espaço se transforma em cenário para o "espetáculo" para uma multidão amorfa mediante a criação de uma série de atividades que conduzem a passividade, produzindo apenas a ilusão da evasão, e, desse modo, o real é metamorfoseado, transfigurado, para seduzir e fascinar.

Ainda para Santos (apud CRUZ, 1999, p. 263) “o espaço turístico é, antes de mais nada, um espaço geográfico e constitui, portanto uma realidade objetiva, um produto social em permanente processo de transformação".

O turismo é chamado por alguns de Geografia Recreativa, uma vez que o turista sai do seu lugar de origem, em direção para outro em busca de lazer, descanso e paz. 0 turismo é assim uma forma de lazer e descanso, seja para adquirir conhecimento e enriquecimento cultural. Segundo Rodrigues (1996, p. 17), pode afirmar ainda que:

0 turismo é incontestavelmente, um fenômeno econômico, político, social e cultural dos mais expressivos das sociedades ditas pós-industriais. Movimenta de forma cada vez mais significativa ao criar e recriar espaços diversificados.

Antes de o turismo chegar, é preciso que os moradores tomem consciência do papel que possuem na- 
quele lugar, saber dá valor à beleza natural ali presente. Neste contexto surge a educação ambiental como um excelente instrumento para o turismo local.

O turismo contemporâneo requer ligação com a educação ambiental e com bases do desenvolvimento sustentável, preocupando-se com a garantia do atendimento ás necessidades das gerações atuais sem prejudicar o atendimento das necessidades das futuras gerações.

\subsection{GEOGRAFIA, TURISMO E EDUCAÇ̃̃O AMBIENTAL: PARCERIAS POSSIVEEIS}

Desde o inicio da década de 1980, discute-se sobre a implantação da educação ambiental para solucionar problemas relacionados com a degradação de áreas naturais. Figueiredo (1996, p. 58) destaca que:

Tem ocorrido um expressivo aumento nos estudos e iniciativas para a definição de diretrizes claras sobre o papel do turismo e suas interfaces com a questão ambiental; alem disso temos percebido um caminhar por trilhas mais propicia na busca do desenvolvimento do ecoturismo de forma responsável e mais integrada com as comunidades atingidas por essas alternativas econômicas e empreendimentos).

Nesse contexto é que foram criadas as Unidades de Conservação (UCs), cujo objetivo principal é proteger áreas naturais, possuindo como instrumento de defesa à restrição do solo, com o envolvimento de entidades do âmbito federal, estadual, municipal e até mesmo particular.

O processo de implantação dessas unidades de conservação ambiental, leva em consideração alguns critérios relacionados à caracterização do local, visando seus aspectos econômicos e sociais, regularização da área, elaboração de um plano de manejo de uso e restrições, e um plano de estruturação físico-administrativa.
As poucas UCs implantadas são questionáveis pois, na maioria dos parques seus planos têm trazido mais problemas que benefícios. Esses problemas estão relacionados à população local, que é vista como mão- de- obra barata para as UCs ( FIGUEIREDO, 1996).

As atividades Ecoturísticas e Educação ambiental possuem papel fundamental no fortalecimento das relações entre população local, equipe das UCs e usuário. Então, num primeiro momento, a atividade ecoturística estará vinculada ao gerenciamento de UCs, seja ela de forma administrativa ou um empreendimento sem um profundo conhecimento das necessidades da localidade. Num segundo momento, a educação ambiental como outro recurso para a meIhoria da estrutura dos projetos das UCs com a ajuda das comunidades.

Para que o turismo ambiental seja bem sucedido, é necessário que haja um compromisso dos administradores de UCs e os empreendedores do ecoturismo em respeitar os moradores da população local e reconhecê-los como parceiros e agentes transformadores. Portanto, o envolvimento participativo entre comunidade e empreendedores do turismo é essencial para a proteção do meio ambiente e, além disso, contribui para o desenvolvimento de opções de empregos, educação e lazer, sem destruir a cultura local. Segundo Figueiredo (1996, p. 62):

\begin{abstract}
Para que essa aproximação efetivamente ocorra, e se multiplique, é necessário amplo processo de reeducação dos técnicos ambientalistas, diminuindo o distanciamento imposto pelo modelo de legislação e pela situação de abandono que rege a UCs no Brasil. É preciso que se proponham atividades mais integradas as realidades socioambientais das regiões onde atuamos.
\end{abstract}

A Geografia é uma ciência que estuda o espaço em sua dimensão, por meio de aspectos sociais, econômicos, humanos, políticos e físicos. Essa ciência, também, depende de outras ciências. Para Callai (1986, p. 17): 
Se o espaço é construído pelos homens, ele vai apresentar uma aparência, uma paisagem que será resultada desta construção. Esta aparência, no entanto, é apenas a organização da paisagem como se estrutura em um determinado momento. $E$ isto resulta das relações que os homens mantêm entre si, intermediados pelo trabatho e subordinados ao modo de produção capitalista. 0 espaço que nós estudamos em Geografia tem que ser compreendido, então, como um espaço que vai sendo construído ao longo do tempo, por homens.

Para a professora de Geografia Spósito (apud OLIVEIRA, 2002, p. 307), há, aqui, um aspecto político, que é o de se oferecer aos alunos, gratuitamente, um dos instrumentos que facilitam o processo de ensinar/ aprender; e há outro que é prático, pois a compra em larga escala permite diminuição do preço de aquisição desse material. Tudo parece indicar que há dificuldades para se produzir livros didáticos voltados de forma precípua a atender especificidades de realidades regionais ou locais, o que reforça as possibilidades de se estabelecer uma relação biunívoca entre currículo nacional e livro didático. Para a autora, os livros didáticos são extremamente importantes para o aprendizado do aluno.

Para os grandes geógrafos, as crises de escola são geradas de vários fatores, principalmente pelo modo tradicional de ensino demonstrado pela maioria de professores que ensina em escolas públicas, seja estadual ou municipal. É a Geografia Crítica que fica responsável pela análise de fatos (histórias reais) que acontecem no espaço geográfico. Para Brabant (apud OLIVEIRA, 2003), pode-se dizer que a crise da geografia na escola se resume essencialmente na crise de sua finalidade. Ensinamento com função ideológica, sua eficácia se vê contestada por discursos mais modernos (economia, sociologia etc.). Marginalizada no momento de adaptação da escola às necessidades profissionais, a geografia está minada por sua aparente incapacidade de dar conta das lutas onde o espaço está em jogo.

É na escola que deve ocorrer à aprendizagem espacial voltada para a compreensão das formas pelas quais a sociedade organiza seu espaço - o que só será plena- mente possível com o uso de representações formais (ou convencionais) desse espaço. A preocupação quanto ao domínio espacial refere-se ao seu desenvolvimento no sentido geográfico, pois a concepção do espaço e sua organização são subjacentes à análise geográfica. Com isso, Almeida (1999, p. 12) destaca que:

Na análise geográfica da organização social do espaço a relação sociedade/natureza se faz através do trabatho que, por ser um ato social, leva as transformações territoriais para a construção de espaços diferenciados conforme os interesses da produção no momento.

Almeida (1999, p. 12) destaca ainda que "no ensino de primeiro grau, esses conhecimentos/habilidades devem ser desenvolvidos e aprofundados desde a primeira até a oitava séries, pois são essenciais ao entendimento dos conceitos que possibilitam ao aluno realizar a análise geográfica".

Essa observação da realidade não é mera identificação de elementos. A partir do levantamento de dados, sua classificação, comparação com outros dados etc., e consequente representação espacial, que na maior parte dos casos é feita por meio de mapas, o aluno chega a generalizações - percebe diversas áreas em que pode ser identificada à mesma situação.

Com todas essas afirmações, é necessário que o educando aprenda a Geografia Física em seu contexto geral e específico para que possa entender os processos em que o planeta Terra vive. 0 aluno deve compreender se sua região (também outras regiões) possui influência da chuva, montanhas, depressões, florestas etc.

Outra abordagem dos ramos da Geografia ensinada no Ensino Fundamental e Médio é a Geografia Humana. É um ramo da Geografia que trata a relação do Homem com os processos sociais, econômicos, culturais e financeiros do espaço em que vive, ou seja, do espaço geográfico. Os problemas humanos persistem maciçamente no cotidiano das pessoas que muitos Geógrafos se preocuparam em estudar bastante a respeito disso. 
Para muitos autores, a Geografia escolar sofre bastante. Isso porque a disciplina faz parte do passivo da velha escola, ou seja, a geografia sofre o contragolpe da emancipação das colônias, na hora em que as estruturas nacionais se inserem nas relações de dependência e se diluem nos espaços mais vastos. Para Oliveira (2003, p. 143), "é na escola que uma parte do processo de conscientização e/ou não conscientização se desenvolve. Todas as disciplinas têm papel a desempenhar nesse processo. À geografia cabe papel singular nesta questão".

O professor de Geografia precisa estar atento nos conteúdos programáticos que irá passar para os alunos. É nele que possuirá a tarefa de mostrar para os educandos uma visão total da realidade brasileira e do planeta Terra.

É necessário que por meio de uma metodologia de ensino demonstrada com segurança e voltada uma postura crítica do educador de Geografia, o aluno formará opiniões sobre os assuntos adquiridos em sala de aula, desenvolvendo sua formação de cidadão esclarecido. Com isso, Oliveira (2003, p. 144) afirma que:

Ou ensinar uma geografia crítica, que forme criticamente a criança, voltada, portanto, para seu desenvolvimento e sua formação como cidadão. Uma geografia preocupada desde cedo com o papel que estas crianças/trabalhadores terão no futuro deste país. Uma geografia que possibilite às crianças, no processo de amadurecimento físico e intelectual, irem formando/ criando um universo crítico que lhes permita se posicionar em relação ao futuro, que thes permita finalmente construir o futuro.

A realidade brasileira sobre a prática de ensino da Geografia no Brasil é pouco confusa. Para muitos autores, os educadores (de um modo geral) não participam ativamente dos processos educativos em sala de aula. Há somente um processo dialético de dominação, sem que haja um questionamento sobre o conteúdo dos livros didáticos e o produto final deles.

As metodologias de ensino aplicadas na Geografia são importantes para o aprimoramento de muitos conteúdos em sala de aula. De acordo com Spósito (apud OLIVEIRA, 2002, p. 299), do ponto de vista da condução metodológica do processo, delineia-se claramente o interesse da centralização, via: formulação de parâmetros curriculares nacionais ( $P C N$ 's) para o ensino fundamental e médio, elaboração de diretrizes curriculares nacionais para o ensino superior, realização do exame nacional de ensino médio (ENEM) etc.

0 processo de ensino-aprendizagem da Geografia precisa ser mais interativo entre professores e alunos. 0 importante desse processo é o domínio do conteúdo do professor, a utilização do livro didático, a função das pesquisas e viagens de campo e conteúdos sendo programáticos para os alunos possuírem um nível de aprendizado e um conhecimento maior da disciplina geográfica.

\section{RELAÇ̃̃ES ENTRE GEOGRAFIA, TURISMO E EDUCAÇÃO AMBIENTAL NO MUNICIPIO DE PIRAMBU}

0 processo de ocupação do turismo está relacionado muitas vezes, ao espaço geográfico. Pois, o fato de o consumidor ter de se deslocar até o produto a ser consumido implica que a prática social do turismo crie ou se aproprie, também, de espaços de deslocamento, iniciando o processo de especulação imobiliária que, ao valorizar novas áreas, faz com que suas características ambientais se tornem completamente secundárias. 
Dessa foram, a noção de respeito às comunidades nativas á algo extremamente difícil de realizar, pois estas comunidades deveriam ter o direito de manter, reproduzir seus valores culturais tradicionais, participar da economia do turismo, estar em contato com os visitantes, para que junto com eles possam criar meios de preservar a natureza e da sua comunidade sem destruir.

Portanto o sentido do termo educação ambiental como processo que busca uma ligação do homem e natureza, e integrá-la ao turismo é de fundamental importância. Logo, pode-se pensar em uma nova forma de preservar a natureza, alem disso, dará a população local e aos turistas a responsabilidade de preservar e respeitar o ecossistema.

\subsection{ASPECTOS GEOGRÁFICOS DE PIRAMBU}

Com base na Lei de $\mathrm{n}^{0} 1234$, de 26 de novembro de 1963, a povoação de Pirambu foi elevada a categoria de cidade dista da capital 76 km, com 199,2 km² de área, estar localizada na micro-região de Japaratuba. (SERGIPE, 2004, p. 340)

Faz limite com os municípios de Pacatuba, Santo Amaro das Brotas, Barra dos Coqueiros, e também com o Oceano Atlântico. A sua hidrografia é formada pela bacia do Rio Japaratuba, rio Pomonga, rio Poxim, rio Papagaio e rio Siriri (SERGIPE, 2004).

Pirambu nasceu de uma colônia de pescadores que os batizaram com o nome de um peixe muito comum na região chamado Pirambu (MUNICIPIO, 2002).

0 município é fortemente marcado pela produção pesqueira. No inicio dos anos 1980, com o surgimento da pesca industrial, ampliou-se o mercado desse produto, tornando o maior centro pesqueiro de Sergipe. Com a criação da Pespesca e a Calne, empresas ligadas à pesca, Pirambu passou a receber migrantes de várias cidades do nordeste e de cidades próximas à região. Essas pessoas contribuíram para o crescimen- to populacional e, econômico e social do município (MUNICIPIO, 2002).

Atualmente o município de Pirambu encontra-se diante de uma série de relacionados à moradia, emprego e outros elementos sociais.

Em termos de emprego, destaque para os seguintes setores: a Prefeitura municipal, a pesca, a agricultura e o turismo. 0 setor público municipal não possui condições de absorver quase nada de mão de obra. A pesca está cada vez mais saturada e em plena empregabilidade, apresenta sérios problemas. A agricultura não apresenta ganhos para a movimentação da economia. 0 turismo ainda não foi explorado de forma adequada, pois Pirambu apresenta belezas naturais, que ainda não foram explorados, restando apenas o turismo em massa motivado nos períodos festivos que age como motor da economia e perspectiva de desenvolvimento da comunidade, mesmo que em pequena quantidade.

Há outros benefícios em Pirambu: a confecção Tamar garante empregos de bordadeiras para as mulheres e filhos dos pescadores e conta com a ajuda dos moradores dessas localidades para a conservação das tartarugas marinhas.

\subsection{TURISMO E RECURSOS NATURAIS}

Apesar de a população de Pirambu sobreviver da pesca, o turismo é também ponto alto do município, onde são realizadas festas conhecidas em todo o Estado. Suas praias e a reserva biológica de Santa Isabel, onde está implantado o Projeto Tamar (preservação das tartarugas marinhas), servem de atrativos para o turismo em massa.

As areias que formam as dunas atrativas. Na Lagoa Redonda, por exemplo, os turistas aproveitam as ondulações para descerem o areal escorregadio sentados na madeira em forma de prancha (na região é chamada de skibunda). 
A vegetação de Pirambu é bastante variada. $\mathrm{Na}$ praia predominamos coqueiros com campos de dunas, mata de restinga e manguezal.

Os principais pontos turísticos que o visitante pode utilizar para o lazer são: Praça da Folia, Praias, Reserva biológica de Santa Isabel, que é o berçário das tartarugas marinhas (Projeto Tamar-IBAMA), cachoeiras, rios, orlas e dunas.

\subsection{EDUCAÇ̃̃o AMBIENTAL E CONSCIENTIZAÇ̄̃̃o ECOLÓGICA}

O enfoque dominante na educação ambiental com a inserção de tópicos ambientais no ensino das ciências e, em alguns casos, buscando-se uma integração com a geografia e a educação artística, tem o intuito de consolidar a educação ambiental como principal forma de sensibilizar as pessoas para o estimulo de se preservar o ambiente.

Acreditava-se que as pessoas estavam distanciadas da natureza e a primeira tarefa da educação ambiental era estabelecer essa ligação, tendo sido desenvolvidas, para tanto, uma série de técnicas nesse sentido. Uma das técnicas seria o termo da ecopedagogia nas escolas com o intuito de dar ênfase a educação ambiental.

A proposta dessa ecopedagogia, de algum modo, vem a ser a reposição da pedagogia de práxis, uma vez que, consagrando a tensão entre a teoria e a prática, ela abrange todas as dimensões da vida social. Nesse sentido, a proposta pedagógica ultrapassa a adesão de projetos de despoluição e a preservação, para vir a compreender um desenvolvimento social e sustentável. Ao mesmo tempo, pretenderam ir além da escola e impregnar toda a sociedade, todos os ambientes.

\subsubsection{GEOGRAFIA E A ESCOLA}

O município de Pirambu possui duas escolas do ensino fundamental, sendo uma da rede pública estadual e a outra municipal.

Segundo o professor de geografia do Colégio Estadual Mário Trindade, Glauber Santos, a escola no seu cotidiano enfrenta diversos problemas, dentre eles o desinteresse dos alunos. Além disso, a comunidade não participa das decisões da escola e a falta de materiais que facilitam a aprendizagem dos alunos, comprometendo assim a passagem do conteúdo.

De acordo com a coordenadora Fabiana Lira, para suprir as necessidades, a escola atua em parceria com o Projeto Tamar e com o professor de geografia que realizam pesquisas de campo, visando a exploração das belezas naturais da região. Além disso, a escola procura atrair os alunos para as atividades como festival das barracas (celebração do São João), feira de ciências, e cultural, gincana cultural e jogos internos.

Um dos maiores desafios do professor de geografia é o de estimular os seus alunos sobre a prática da educação ambiental. Para isso, o educador procura conscientizar seus alunos a importância de se preservar o meio ambiente, por meio da caminhadas e palestras com o intuito de criar um sentimento de respeito entre eles.

Portanto, preservar o local, tirar o lixo das ruas, preservar as espécies são ações que o professor de geografia deverá expor para os seus alunos como forma de devolver a prática da educação ambiental nas escolas. 


\section{CONSIDERACÕES FINAIS}

0 estudo sobre a relação entre educação ambiental, turismo e meio ambiente do município de Pirambu, foi de fundamental importância para o desenvolvimento desse artigo. Isso, porque foram identificados aspectos sociais e geográficos, bem como a relação entre geografia e educação ambiental e seus reflexos no despertar da conscientização ecológica da população que sofre com impactos ambientais.

A importância da atividade da educação ambiental para a atividade turística tem a função de conhecer, divulgar e preservar o patrimônio histórico, cultural e natural. Além disso, traz algumas referências sobre a prática do turismo e seus vínculos com a questão do desenvolvimento local e os conflitos gerados com as comunidades envolvidas diretamente com esse tipo de atividade, principalmente no que tange ao manejo de das áreas naturais protegidas.

A educação ambiental, por sua natureza complexa e interdisciplinar, que envolve aspectos da vida cotidiana, questiona a qualidade de vida e explicita as interdependências entre ambiente e sociedade. Buscando construir cada vez mais a autonomia do cidadão para que possam transformar a realidade em que vivem.
A proteção do meio ambiente está ao alcance de todos os cidadãos, pelo menos em teoria. Quanto à prática, deixa a desejar, pois quando se trata em correr em defesa do ambiente, o ser humano se mostra rápido no gatilho, propenso sempre ao radicalismo, esquecidos de que existe uma opção, um meio termo entre desenvolvimento e preservação. Para que o meio possa ser salvo, é preciso que os movimentos ecológicos em defesa do ambiente saibam entrar em acordo com os empresários que exploram a natureza de forma a não prejudicar o ecossistema.

Portanto, o desenvolvimento da consciência ecológica repõe problemas de profundidade extraordinária: os alicerces da sociedade moderna, a intensidade de ocupação populacional dos espaços geográficos, o predomínio da razão sobre as outras dimensões humanas. Além disso, interfere no destino da sociedade, da cultura e do individuo.

Em Pirambu, a relação geografia, educação ambiental, turismo e conscientização ecológica deverão manter interdependência com as práticas educativas ma escola, no processo de formação do homem cidadão.

Essa conscientização deverá ser realizada desde a escola, tendo a geografia e as ciências humanas como fatores decisivos para a aplicação da educação ambiental. 


\section{REFERÊNCIAS}

ALMEIDA, Rosângela Doin de. 0 espaço geográfico: ensino e representação. São Paulo: Contexto, 1999.

CALLAI, Jaeme Luiz. Área de Estudos Sociais. Ijuí: Unijuí, 1986.

CARLOS, Ana Fani Alessandri de. Turismo e Produção de não lugar. In: YÁZIGI, Eduardo (org). Turismo: Espaço, Paisagem e Cultura. São Paulo: Huritec, 1996, p. 26.

CORIOLANO, Luzia Neide M. T. de. Turismo e Degradação Ambiental no Litoral do Ceará. In: LEMOS, Amália Ines G. de (Org). Turismo Impactos socioambientais. São Paulo: Huritec, 1996, p. 94-102.

CRUZ, Rita de Cássia Ariza da. Introdução à Geografia do Turismo. São Paulo: Roca, 1999.

FIGUEIREDO, Luiz Afonso Vaz de. Ecoturismo e participação popular no manejo de áreas protegidas. In: RODRIGUES, Adyr B. (org). Turismo, Meio ambiente Reflexões e Propostas. São Paulo: Huritec, 1996, p. 58-63.

MARTINS Junior, Osmar Pires. Uma Cidade Ecologicamente Correta. Goiânia, GO : AB, 1996.
MIDAGLIA, Carmem Lúcia Vergueiro de. Turismo e Meio Ambiente no Litoral Paulista: Dinâmica da Balneabilidade nas Praias In: LEMOS, Amália Ines G. de (Org). Turismo Impactos socioambientais. São Paulo: Huritec, 1999, p. 40-42.

OLIVEIRA, Ariovaldo Umbelino de. Geografia em Perspectiva: ensino e pesquisa. São Paulo: Contexto, 2002.

OLIVEIRA, Ariovaldo Umbelino de. Para onde vai o ensino da Geografia? São Paulo: Contexto, 2003.

RODRIGUES, Arlete Moysés de. A produção e o consumo do espaço para o turismo e a problemática ambiental. In: YÁZIGI, Eduardo (Org). Turismo: Espaço, Paisagem e Cultura. São Paulo: Huritec, 1996, p. 5558

RUSCHMANN, Doris Van de Meene. Turismo e planejamento sustentável : a proteção do meio ambiente. Campinas, SP: Papirus, 2001.

Sergipe Panorâmico / Universidade Tiradentes; Organizações [de] Joubeto Uchôa de Mendonça e Maria Lucia Marques Cruz E Silva - Aracaju: UNIT, 2002.

Recebido em: 3 de Outubro de 2013 